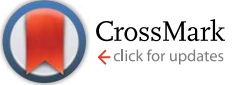

Cite this: RSC Adv., 2015, 5, 76795

\title{
Synergistic strategies for the preparation of highly efficient dye-sensitized solar cells on plastic substrates: combination of chemical and physical sintering $\dagger$
}

\begin{abstract}
Yuelong Li,,$^{\text {ab }}$ Kicheon Yoo, $\neq^{\text {ac }}$ Doh-Kwon Lee, ${ }^{\text {ad }}$ Jin Young Kim, ${ }^{\text {ae }}$ Hae Jung Son, ${ }^{a}$ Jong Hak Kim, ${ }^{c}$ Chul-Ho Lee, ${ }^{e}$ Hernán Míguez ${ }^{* b}$ and Min Jae Ko*adf

Preparation of well-interconnected $\mathrm{TiO}_{2}$ electrodes at low temperature is critical for the fabrication of highly efficient dye-sensitized solar cells (DSCs) on plastic substrates. Herein we explore a synergistic approach using a combination of chemical and physical sintering. We formulate a binder-free $\mathrm{TiO}_{2}$ paste based on "nanoglue" as the chemical sintering agent, and use it to construct a photoelectrode on plastic by low-temperature physical compression to further improve the connectivity of $\mathrm{TiO}_{2}$ films. We systematically investigated the factors affecting the photovoltaic performance and found the conditions to achieve electron diffusion lengths as long as $25 \mu \mathrm{m}$ and charge collection efficiencies as high as $95 \%$, as electrochemical impedance spectroscopy measurements indicate. We apply this approach to obtain a DSC deposited on plastic displaying 6.4\% power conversion efficiency based on commercial P25 titania particles.
\end{abstract}

Received 31st May 2015
Accepted 3rd September 2015

DOI: $10.1039 / c 5 r a 10290 a$

www.rsc.org/advances temperature of approximately $500{ }^{\circ} \mathrm{C}$. Up to now, many low temperature fabrication processes have been reported, and most of them can be categorized into chemical and physical sintering methods. As for the latter, the compression ${ }^{\mathbf{1 6}}$ method has been considered as a quick and simple technique to fabricate well interconnected $\mathrm{TiO}_{2}$ film for highly efficient DSCs on plastic substrates. ${ }^{17}$ Recently, we developed novel chemical sintering method using the concept of an inorganic interparticle agent, ${ }^{5,6}$ coined "nanoglue", for inducing the chemical bonding of neighboring $\mathrm{TiO}_{2}$ nanoparticles during thermal treatment; this allowed to build cells that reached $5.4 \%$ efficiency at the low temperature of $130{ }^{\circ} \mathrm{C}$ so to preserve the thermal stability of the plastics involved. Although there have been several studies on the individual effects of chemical and physical sintering effect on the performance of plastic DSCs, there is few report on the plastic DSCs prepared from both physical and chemical sintering methods. It would be of great interest to combine the compression, or physical sintering with the nanoglue based chemical sintering, for the preparation of highly efficient DSCs on plastic substrates.

In this manuscript, we analyze the effect of combining chemical sintering with physical sintering and demonstrate plastic supported solar cells that reach a power conversion efficiency of $6.4 \%$ based on commercial available P25 titania particles, which is quite state-of-the-art value compared with that of previously published based on the home-made titania particles. This synergic strategy relies on the use of a binder-free paste containing nanoglue and then compression $\dagger$ Electronic supplementary information (ESI) available. See DOI: 10.1039/c5ra10290a

\$ These authors contribute equally to this work. 
simultaneously with being sintered at $130{ }^{\circ} \mathrm{C}$. Systematic investigation of the factors affecting the performance of DSCs prepared by this combined method was carried out; the optimum pressure applied on the glued nanocrystalline pastes to maximize electron diffusion length and collection was found.

\section{Experimental}

$20 \mathrm{wt} \% \mathrm{TiO}_{2}$ particles (P25, $21 \mathrm{~nm}$, Degussa) in ethanol solution were dispersed by Ultra Apex Mill (Model UAM-015, Kotobuki). An interparticle binding agent, or nanoglue, was synthesized by a sol-gel process following a published procedure. ${ }^{5}$ The nanoglue containing anatase $\mathrm{TiO}_{2}$ particles of $5 \mathrm{~nm}$ size were added to induce good interparticle connection at low temperature. Large $\mathrm{TiO}_{2}$ particles (T030, 320 nm, K. K. Titan, Japan) were used to cause multiple scattering within the electrode and hence enhance light harvesting.

The viscous binder-free paste was prepared according to the following procedure: dispersed P25 particles, small particles from nanoglue gel and large T030 particles were mixed and dispersed by tip sonication (Q500 Sonicator, Qsonica) followed by vigorous shaking with a vortex mixer for at least $10 \mathrm{~min}$ each. The weight ratio of particles of P25: T030 : nanoglue is optimized to $55: 30: 15$. The solid content of the particle mixture in the final pastes was fixed at $15 \mathrm{wt} \%$.

The $\mathrm{TiO}_{2}$ films were spread using a doctor blade onto a transparent conducting plastic substrate (ITO/PEN, $200 \mu \mathrm{m}$ thick, $15 \Omega \mathrm{sq}^{-1}$, transmittance of $80 \%$ at $550 \mathrm{~nm}$, Peccell Tech. Inc.); $3 \mathrm{M}$ tape is used as a spacer. After drying at ambient temperature, $\mathrm{TiO}_{2}$ films were compressed at with temperature of $130{ }^{\circ} \mathrm{C}$ for $5 \mathrm{~min}$ with a lamination apparatus (Creative \& Innovation System, Korea). A thin Teflon film was inserted between the $\mathrm{TiO}_{2}$ film and the piston to avoid contamination and film removal during compression. Compressed films were immersed into $0.5 \mathrm{mM} \mathrm{N} 719$ (cis-bis(isothiocyanato)-bis(2,2'-bipyridyl-4,4'dicarboxylato)-ruthenium(II) bis-tetrabutylammonium), anhydrous ethanol solution for dye loading at $40^{\circ} \mathrm{C}$ for $3 \mathrm{~h}$ with continuous shaking. Pt counter electrode was prepared by spreading a drop of $7 \mathrm{mM}$ of $\mathrm{H}_{2} \mathrm{PtCl}_{6} \cdot 6 \mathrm{H}_{2} \mathrm{O}$ in 2-propanol on a glass substrate (FTO/glass, $8 \Omega \mathrm{sq}^{-1}, 2.3 \mathrm{~mm}$-thick, Pilkington TEC8), drying at ambient temperature and annealing at $400{ }^{\circ} \mathrm{C}$ for $20 \mathrm{~min}$. The two electrodes were assembled using $60 \mu \mathrm{m}$-thick hot melt Surlyn (Dupont 1702). The standard electrolyte solution was composed of $0.7 \mathrm{M}$ 1-propyl-3-methylimidazolium iodide (PMII), $0.03 \mathrm{M}$ iodine $\left(\mathrm{I}_{2}\right), 0.05 \mathrm{M}$ guanidinium thiocyanate (GuSCN) and $0.5 \mathrm{M}$ 4-tert-butylpyridine $(t \mathrm{BP})$ in a mixture of acetonitrile and valeronitrile $(\mathrm{v} / \mathrm{v}=85: 15)$; it was introduced through the drilled holes on the counter electrode. The active area of the dye-adsorbed $\mathrm{TiO}_{2}$ films was about $0.45 \mathrm{~cm}^{2}$ as measured by an image analysis program equipped with a digital microscope camera (Moticam 1000). The thickness of the $\mathrm{TiO}_{2}$ films was measured by an Alpha-step IQ surface profiler (KLA Tencor).

The amounts of dye adsorbed on the $\mathrm{TiO}_{2}$ films were quantitatively estimated by desorbing the dye in basic solution, as follows: the sensitized films with known areas and thicknesses were rinsed by anhydrous ethanol and then dried in a dry nitrogen flow. The films were immersed in a measured volume of $0.1 \mathrm{M} \mathrm{NaOH}$ solution in water/ethanol (50:50 v/v) for $24 \mathrm{~h}$ to remove the dye molecules from the $\mathrm{TiO}_{2}$ films. The UV-Vis absorption spectrum of the resultant solution was recorded using a Perkin-Elmer Lambda 35 UV-Vis spectrometer, as shown in Fig. $\mathrm{S} 1$ in the ESI. $\dagger$

High-resolution transmission electron images (HR-TEM) were obtained using a Field-Emission-Gun-equipped TEM instrument (FEI Tecnai F20, Philips Electron Optics, Holland). Photocurrent-voltage measurements were performed using a Keithley 2400 source measure unit. A solar simulator (Yamashida Denso) equipped with a $1000 \mathrm{~W}$ Xe lamp was used as a light source. Light intensity was adjusted employing an NRELcalibrated Si solar cell. A black mask was placed on top of the cells to prevent diffusion of light during measurement. The incident photon-to-current conversion efficiency (IPCE) was measured using a system specifically designed for DSCs (PV measurements, Inc.). The electrochemical impedance spectra (EIS) were attained in the frequency range of $10^{-1}$ to $10^{6} \mathrm{~Hz}$ using a potentiostat (Solartron 1287) equipped with a frequency response analyzer (Solartron 1260); the magnitude of the alternate signal was $10 \mathrm{mV}$. Impedance parameters were determined by fitting the impedance spectrum using Z-view software. The impedance measurements were carried out in the dark by sweeping the applied potential.

\section{Results and discussion}

The structural and morphological properties of films composed of ternary particles were examined by transmission electron microscopy (TEM). The films were scratched off the substrates and deposited on a microscope grid. In Fig. 1(a), it can be seen that smaller particles, composing the actual nanoglue, fill the voids between the larger P25 and T030 scattering particles, and continuously connect larger particles together to yield a more compact structure which potentially reduce pore size and porosity of resulted films. From the enlarged image in Fig. 1(b), the crystallinity and size of small nanoglue particles can be clearly seen, which is pure anatase phase for crystallinity and about $5 \mathrm{~nm}$ for the size. After compression, the morphology and structure of both the surface (left column, Fig. 2) and the cross section (right column, Fig. 2) of the films were characterized by scanning electron microscopy (SEM). It was observed that the ternary particle composition films compressed at $0 \mathrm{MPa}$, corresponding to film without compression, display a smooth surface without any cracks (Fig. 2(a)), which is a basic requirement to achieve a reasonable cell performance; cracks within a film have a dramatic effect on the electron transport between neighboring particles and hence deteriorate the photovoltaic performance. ${ }^{10,18}$ Additionally, a mesoporous structure was observed from the cross-view of SEM in Fig. 2(b). More SEM images were obtained of the films pressed at $40 \mathrm{MPa}, 100 \mathrm{MPa}$ and $160 \mathrm{MPa}$ in order to examine the effect of applying different and increasing pressures on film morphology. Fig. 2(c) exhibit a film pressed at $40 \mathrm{MPa}$, it shows that the surface becomes more flat with compression; the effect is more significant for films compressed at $100 \mathrm{MPa}$ and $160 \mathrm{MPa}$, as shown in Fig. 2(e) and 
(g). The surface roughness of the films was evaluated from the three-dimensional images of atomic force microscopy (AFM) (Fig. $\mathrm{S} 2 \dagger)$. The root mean square roughness $\left(R_{\mathrm{q}}\right)$ significantly decreases from $47.66 \mathrm{~nm}$ for uncompressed film to $15.95 \mathrm{~nm}$ for compressed films at $40 \mathrm{MPa}$, and continues gradually decreasing to $11.71 \mathrm{~nm}$ and $5.27 \mathrm{~nm}$ for compressed films at $100 \mathrm{MPa}$ and $160 \mathrm{MPa}$, respectively. The reduced $R_{\mathrm{q}}$ indicates flattened surface by compression. We quantitatively investigated the structural properties related to pore in the film using Barrett-Joyner-Halenda (BJH) pore size and volume analysis. As summarized in Table S1, $\dagger$ compressed films hold both smaller pores and less porosity with increasing applied pressure. The reduction of porosity with increasing pressure may be due to the reduction of the interparticle space with the closer packing of the nanoparticles; the packing could partially shift from a relatively loose cubic pileup to the denser tetrahedral pileup as schematized in Fig. S3. $\dagger$ According to BJH analysis, the porosity $(P)$ of compressed films are $41.8 \%, 34.0 \%, 25.6 \%$, and $22.8 \%$ for applied pressures of $0 \mathrm{MPa}, 40 \mathrm{MPa}, 100 \mathrm{MPa}$, and $160 \mathrm{MPa}$, respectively, which presents similar tendency with a previous report, ${ }^{8}$ The average nanoparticle coordination number $(N)$ for ternary composition films subjected to different pressures was estimated according to the approximate expression: ${ }^{19-21}$

$$
N=(3.08 / P)-1.13
$$

Values of $N=6.2, N=7.9, N=10.9$ and $N=12.4$ are obtained for the films compressed at $0 \mathrm{MPa}, 40 \mathrm{MPa}, 100 \mathrm{MPa}$, and $160 \mathrm{MPa}$, respectively. For a particle network to be mechanically stable, the average $N$ has to be at least $3 .^{20}$ Hence, our results are in good agreement with the observation of crackfree films in all cases by SEM..$^{20,21}$ Furthermore, better electron transport between nanoparticles is expected for structures with higher values of $N$.

The average photovoltaic properties of cells based on compressed films with thickness of about $6.5 \mu \mathrm{m}$ were summarized in Table 1; graphical representation together with photocurrent-voltage, IPCE curves of these data can also be found in Fig. S4. $\dagger$ As clearly seen in Table 1, the cell which was just dried at room temperature in air without compression has the lowest efficiency; we use the photovoltaic parameters values of this cell as our reference. After compression at $40 \mathrm{MPa}$, the short-circuit current $\left(J_{\mathrm{sc}}\right)$ of the cells is remarkably enhanced from $5.42 \mathrm{~mA} \mathrm{~cm}{ }^{-2}$ to $8.46 \mathrm{~mA} \mathrm{~cm}{ }^{-2}$. The $J_{\mathrm{SC}}$ continuously increases with increasing compression and reaches a maximum of $9.64 \mathrm{~mA} \mathrm{~cm}^{-2}$ at a pressure of $100 \mathrm{MPa}$; a $78 \%$ improvement with respect to the reference is observed. Such significant enhancement in $J_{\mathrm{SC}}$ can be attributed to the enhanced interparticle connectivity caused by compression. Interestingly, $J_{\mathrm{SC}}$ began to decrease with further increase of compression pressure, as will be discussed later. On the other hand, the open circuit voltage $\left(V_{\mathrm{OC}}\right)$ increases from $778 \mathrm{mV}$ in the reference cell to approximately $795 \mathrm{mV}$ in the cell in which the electrode is compressed at $40 \mathrm{MPa}$; no significant variations are observed after further compression. The fill factor (FF) shows similar tendencies to the $V_{\mathrm{OC}}$. The power conversion efficiency $(\eta)$
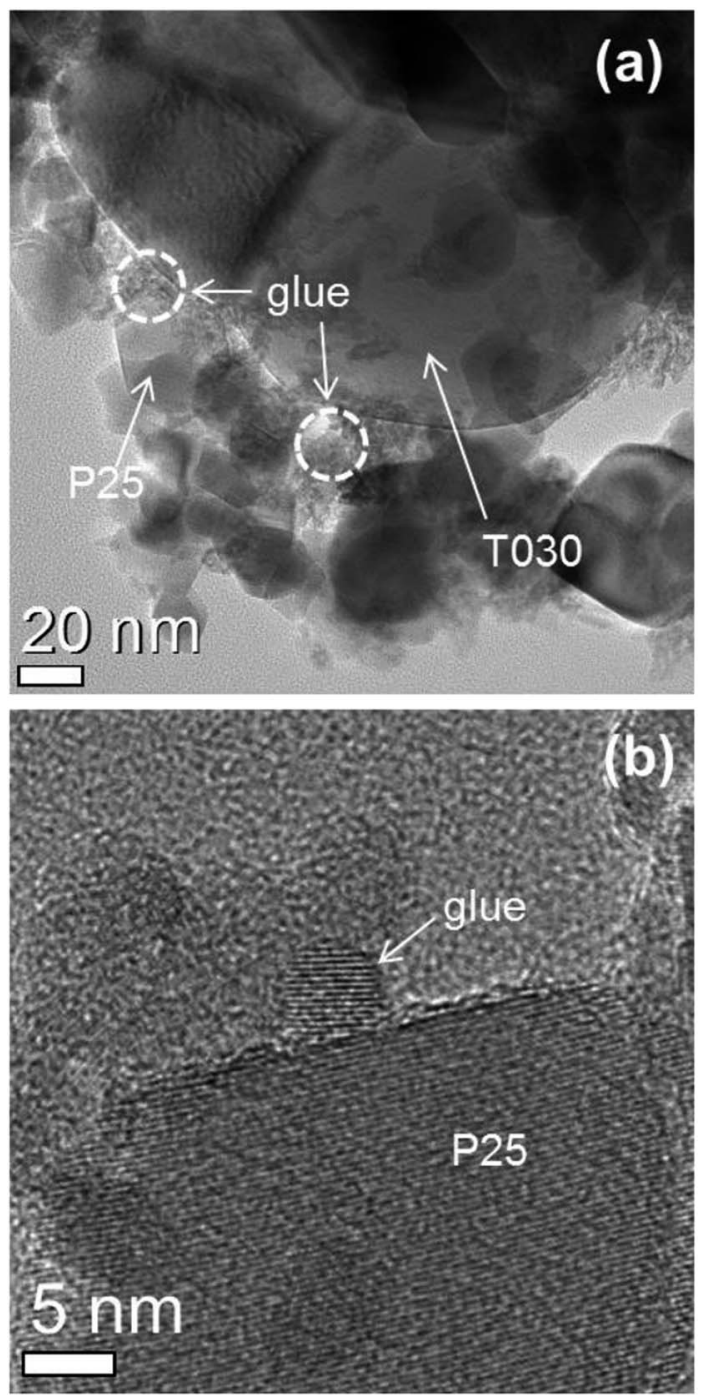

Fig. 1 TEM images of $\mathrm{TiO}_{2}$ films that were partially removed from the substrate prior to compression (a) and enlarged image (b).

follows the same trend as the $J_{\mathrm{SC}}$ and a significantly increase from $2.86 \%$ to $5.31 \%$ is observed after compression at 100 MPa. Unlike the significant increase of cell performance from $2.86 \%$ for uncompressed cell to $4.66 \%$ for compressed cell at $40 \mathrm{MPa}$, the increment of performance was not so noticeable when higher compression force were applied. This is probably due to the trade-off relationship between interconnectivity of nanoparticles and mass transport (ionic diffusion) of electrolyte in the pores. Higher compression could induce tighter interparticle connection, which is favorable for the electron transport, but at the same time, it could reduce the porosity of films and pores size, which would retard the electrolyte diffusion in the pores. Consequently, the degree of compression affects the cell performance. Under our experimental conditions, compressed cells with $100 \mathrm{MPa}$ always presented the best cell performance and highest average performance, which is in good agreement with previous observations for compressed cells. ${ }^{2,10}$ 

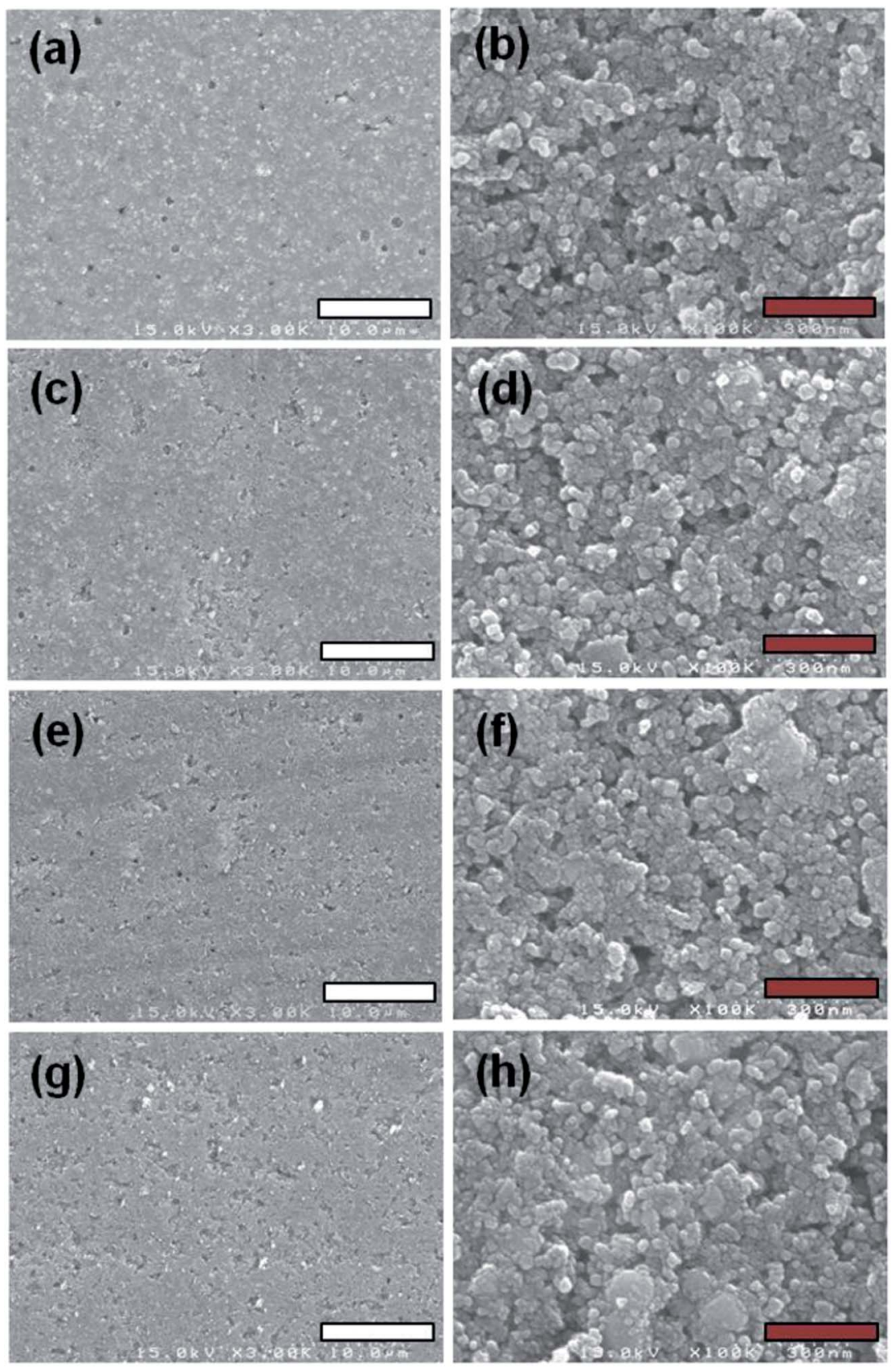

\section{$10 \mu \mathrm{m}$}

\section{$300 \mathrm{~nm}$}

Fig. 2 SEM images of films pressed with various compression forces showing film morphologies and structures. For comparison, films prepared with a compression pressure of $0 \mathrm{MPa}$ ( $\mathrm{a}$ and b), $40 \mathrm{MPa}$ (c and d), $100 \mathrm{MPa}$ (e and f), and $160 \mathrm{MPa}$ ( $\mathrm{g}$ and h) are observed. The images in the left column are of surface morphologies and those in the right column are of cross-section morphologies.

It is also worth mentioning that the most efficient reference cell reached an efficiency of $3.02 \%$, which is comparable or even higher than many published results for films produced with physical compression or sintering treatment; ${ }^{22,23}$ this demonstrates the beneficial effect of using nanoglue in the binder-free paste. The synergic effect of physical compression and chemical sintering was confirmed by evaluating the effect of heating a ternary particle based electrode to $130{ }^{\circ} \mathrm{C}$ without applying any pressure; a cell displaying a $4.50 \%$ power conversion efficiency was obtained. $\eta$ is well below $5.38 \%$ which was attained for a cell with electrodes that had been simultaneously compressed and chemically sintered at $130{ }^{\circ} \mathrm{C}$; comparative data is provided in Table S2. $\dagger$

A series of studies were conducted to determine the origin of the enhancement of the photovoltaic properties by simultaneous chemical sintering and compression. Due to its dominant role in determining cell efficiency, parameters affecting 
Table 1 Photovoltaic properties of cells compressed with various compression forces. The electrolyte is composed of $0.7 \mathrm{M} \mathrm{PMII}, 0.03 \mathrm{M}$ 12, $0.05 \mathrm{M}$ GuSCN and $0.5 \mathrm{M}$ tBP in a mixture of acetonitrile and valeronitrile $(\mathrm{v} / \mathrm{v}=85: 15)$. The data is averaged from at least three points

\begin{tabular}{lllll}
\hline Sample & $J_{\text {SC }}\left(\mathrm{mA} \mathrm{cm}^{-2}\right)$ & $V_{\text {OC }}(\mathrm{V})$ & FF & $\eta(\%)$ \\
\hline $0 \mathrm{MPa}$ & $5.42 \pm 0.26$ & $0.778 \pm 0.005$ & $0.68 \pm 0.01$ & $2.86 \pm 0.16$ \\
$40 \mathrm{MPa}$ & $8.46 \pm 0.29$ & $0.788 \pm 0.007$ & $0.70 \pm 0.01$ & $4.66 \pm 0.21$ \\
$60 \mathrm{MPa}$ & $8.68 \pm 0.24$ & $0.793 \pm 0.004$ & $0.69 \pm 0.02$ & $4.78 \pm 0.13$ \\
$80 \mathrm{MPa}$ & $8.75 \pm 0.13$ & $0.786 \pm 0.007$ & $0.70 \pm 0.01$ & $4.82 \pm 0.10$ \\
$100 \mathrm{MPa}$ & $9.64 \pm 0.04$ & $0.797 \pm 0.003$ & $0.69 \pm 0.01$ & $5.31 \pm 0.10$ \\
$120 \mathrm{MPa}$ & $9.29 \pm 0.28$ & $0.796 \pm 0.008$ & $0.70 \pm 0.01$ & $5.18 \pm 0.17$ \\
$140 \mathrm{MPa}$ & $8.59 \pm 0.68$ & $0.794 \pm 0.014$ & $0.68 \pm 0.01$ & $4.67 \pm 0.38$ \\
$160 \mathrm{MPa}$ & $8.03 \pm 1.07$ & $0.798 \pm 0.021$ & $0.71 \pm 0.02$ & $4.54 \pm 0.48$
\end{tabular}

the $J_{\mathrm{SC}}$ were first considered. $J_{\mathrm{SC}}$ is the product of light harvesting by the dye, electron injection (from the excited state of the dye to the conduction band of $\mathrm{TiO}_{2}$ ), and charge collection efficiencies. ${ }^{24}$ The dye load of each compressed electrode was examined according to the procedures described in the experimental section. Fig. 3 is a plot of the dye load and $J_{\mathrm{SC}}$ as a function of the compression pressure; it can be seen that even when the dye load was slightly reduced, the $J_{\mathrm{SC}}$ gradually increased with compression pressure as the structure densified. As long as the amount of absorber is basically preserved, the observed increase in $J_{\mathrm{SC}}$ should be attributed to either improved charge injection or electron diffusion; improved charge injection is not expected to be affected by compression, while electron diffusion depends on the phenomena of electron transport and recombination. The reason for the increase in $J_{\mathrm{SC}}$ was investigated using electrochemical impedance spectroscopy (EIS) under one-sun illumination with open circuit and in the dark with applied forward potential. The frequency resolved information at the individual interfaces can be quantitatively investigated by fitting Nyquist plots to proper equivalent models. ${ }^{25-27}$ It is generally known that the semicircles occurring in the range of $10^{1}$ to $10^{2} \mathrm{~Hz}$ and $10^{2}$ to $10^{3} \mathrm{~Hz}$ are related to the charge transfer process at the $\mathrm{TiO}_{2} /$ electrolyte interface and the injection of electrons into the $\mathrm{TiO}_{2}$ films, respectively. The higher frequency semicircles (in the $\mathrm{kHz}$ range) are associated with charge transfer at the Pt counter electrode and/or electrical contact between the ITO/TiO ${ }_{2}$ films. Semicircles at lower frequencies (less than $10 \mathrm{~Hz}$ ) represent redox ionic diffusion within the electrolyte. ${ }^{28}$ The impedance spectra were first recorded at one sun illumination with open circuit condition and typical Nyquist plots were obtained (Fig. 4). As seen in Fig. 4(a), the impedance arc of films produced without compression was a little distorted in the range used for the estimation of electron transport resistance in $\mathrm{TiO}_{2}$ films. ${ }^{29}$ The distortion is usually originates from poor connection between $\mathrm{TiO}_{2}$ nanoparticles and indicates that the electron transport resistance is much greater than charge transfer resistance at the $\mathrm{TiO}_{2} /$ electrolyte interface. ${ }^{12}$ Contrarily, all compressed films display the typical three-semicircles, which can be clearly decoupled, implying enhanced interconnection within the $\mathrm{TiO}_{2}$ photoelectrodes after compression. Spectra were fitted using the equivalent circuit model and the results are summarized in Table S3. $\dagger$ The resistance $\left(R_{1}\right)$, estimated from the semicircle at high frequency, generally includes information on the charge transfer at the counter electrode and the electrical contact between $\mathrm{TiO}_{2}$ and ITO substrates. As the same platinized counter electrodes are used for all cells, differences in $R_{1}$ may be mainly ascribed to variations of the electrical contact resistance between the $\mathrm{TiO}_{2}$ films and ITO substrates. $R_{1}$ was significantly reduced from 5.82 to $1.89 \Omega$ after simultaneous chemical sintering and compression, highlighting the good adhesion between the $\mathrm{TiO}_{2}$ films and ITO substrates in the compressed films. The resistance $R_{2}$, extracted from the analysis of the second semicircle, carries information on the charge transfer process at the interface between the $\mathrm{TiO}_{2}$ and the electrolyte.

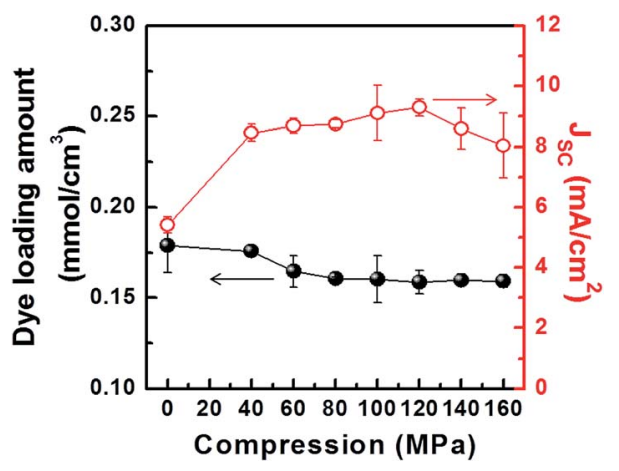

Fig. 3 The dye loading amount for films compressed with various compression forces. For comparison, the averaged $J_{S C}$ from three cells made of same condition was also plotted.

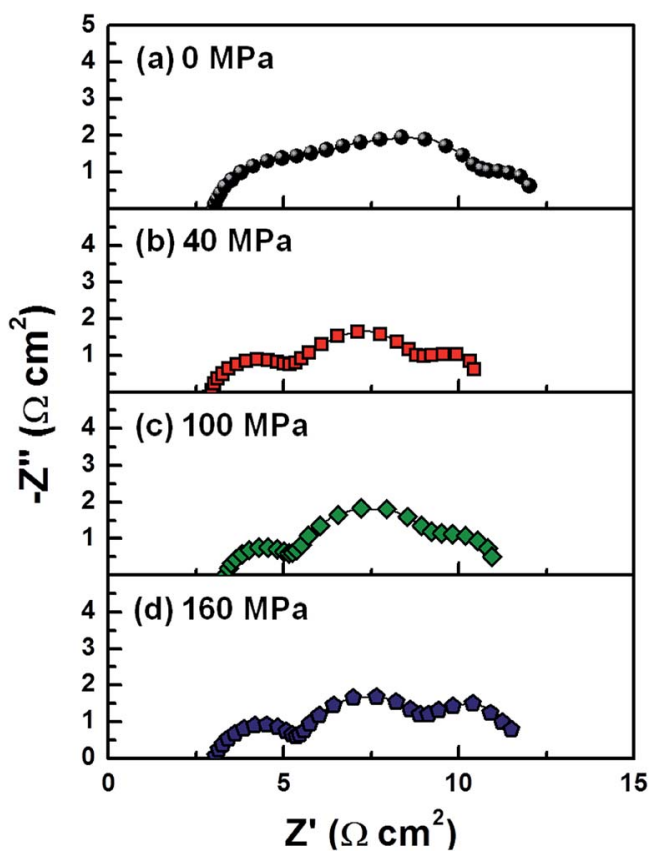

Fig. 4 Nyquist plots of impedance spectra from cells prepared with compression forces of $0 \mathrm{MPa}, 40 \mathrm{MPa}, 100 \mathrm{MPa}$, and $160 \mathrm{MPa}$; spectra were recorded at one-sun illumination with open circuit condition. 
The relatively higher values of $R_{2}$ attained from cells based on compressed films indicate less recombination in the cells with compressed films, which led to a relatively higher observed $V_{\text {OC }}$ for cells containing compressed films. Finally, the effect of compression on the diffusion of electrolyte within the $\mathrm{TiO}_{2}$ films was determined by evaluating the Warburg impedance $\left(W_{1}\right)$. Larger $W_{1}$ was found from the films under analysis; this indicates that the reduced porosity resulting from compression hinders ionic diffusion of redox ionic species. The diffusion coefficients $\left(D_{\mathrm{R}}\right)$ were also calculated based on the fitted data of low frequency semicircles as follows: ${ }^{28}$

$$
D_{\mathrm{R}}=(1 / 2.5) \delta^{2} \omega_{\max }
$$

where $\delta$ is the cell gap between two electrodes and $\omega_{\max }$ is the peak frequency of the low frequency arc; a $\delta$ of $16 \mu \mathrm{m}$ is used in this study. According to the calculated results (Table S3†), we find that the maximum value of $D_{\mathrm{R}}$ is obtained from films produced without compression. The poorer electrolyte diffusion in compressed films seems to gradually affect the dye regeneration and hence the $J_{\mathrm{SC}}$, especially with compression pressures greater than $100 \mathrm{MPa}$; poor electrolyte diffusion in the cells with compressed films could also result in a decline of the electron transport behavior in $\mathrm{TiO}_{2}$ film.

Cells were also evaluated by EIS in the dark with a variation of bias voltage using the transmission line model. By interpreting these measurements, in contrast to those realized under illumination with open circuit voltage, electron transport within the $\mathrm{TiO}_{2}$ network and charge transfer at the interface of $\mathrm{TiO}_{2} /$ electrolyte could be more clearly evaluated. While decreasing the forward bias potential from 0.75 to $0.55 \mathrm{~V}$, electron transport in the mesoscopic $\mathrm{TiO}_{2}$ film is characterized by a Warburglike diffusion behavior in the high-frequency region (a straight line) and mid-frequency region (a large semicircle)corresponding to an interfacial charge recombination processes..$^{26,28,30}$ The reaction of photogenerated electrons with the $\mathrm{I}_{3}{ }^{-}$ions at the
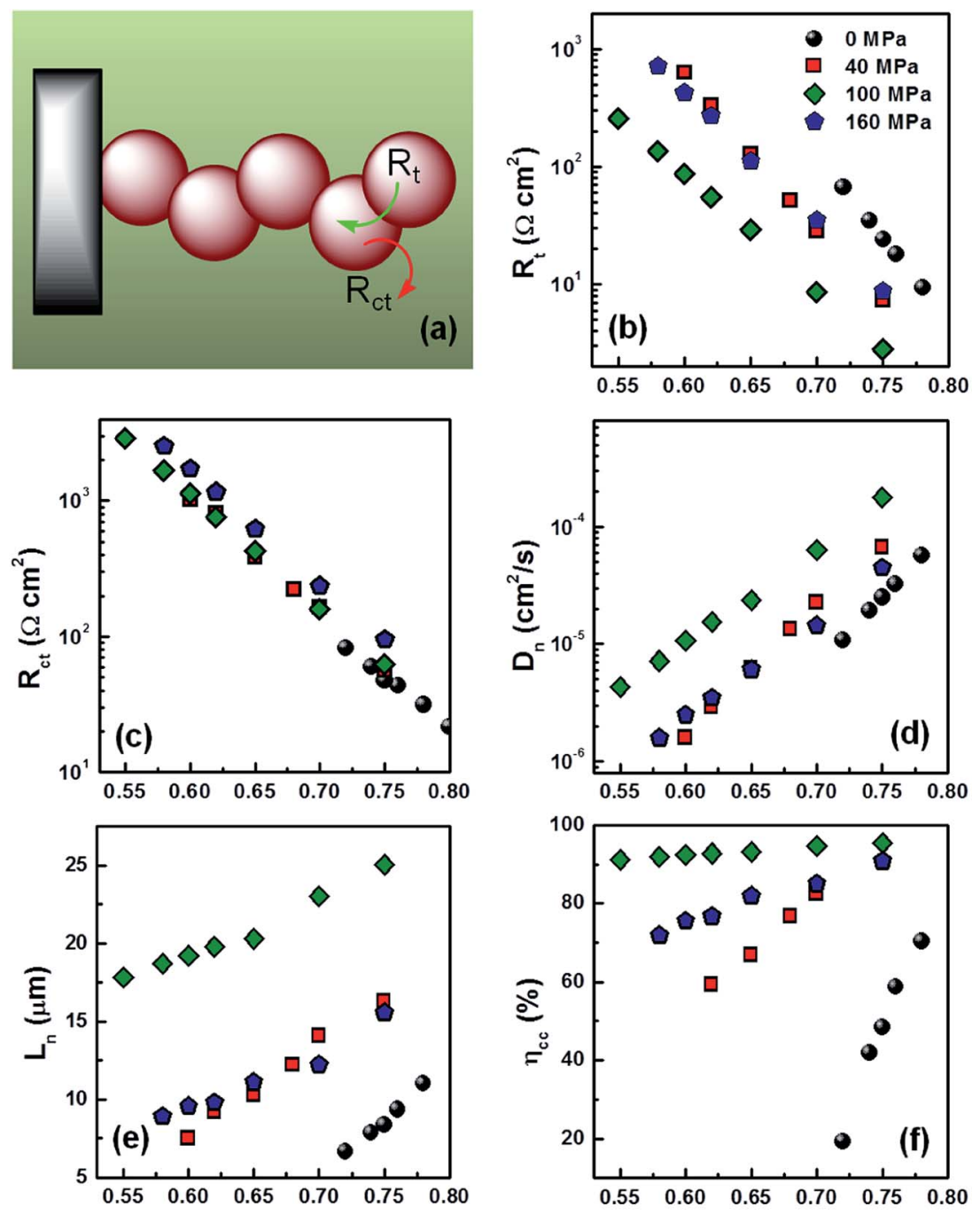

Bias potential (V)

Fig. 5 Schematic of electron transport and recombination (a). The fitted $R_{\mathrm{t}}$ (b), $R_{\mathrm{ct}}$ (c) and calculated $D_{\mathrm{n}}$ (d), $L_{\mathrm{n}}$ (e), $\eta_{\mathrm{cc}}$ (f) of compressed films at various compression forces as measured in the dark by electrochemical impedance spectroscopy. 
$\mathrm{TiO}_{2} /$ electrolyte interface typically depends on the transport of both the electrons within the interconnected $\mathrm{TiO}_{2}$ nanoparticles chains and the redox species throughout the pore network of the mesostructure. If $L$ is the thickness of the $\mathrm{TiO}_{2}$ film, then the electron transport resistance in the $\mathrm{TiO}_{2}$ film is $R_{\mathrm{t}}=r_{\mathrm{t}} L$, where $r_{\mathrm{t}}$ is the inter-particle resistance. The overall recombination resistance is $R_{\mathrm{ct}}=r_{\mathrm{ct}} / L$ where $r_{\mathrm{ct}}$ is the charge-transfer resistance opposing the recombination process between electrons in the mesoscopic $\mathrm{TiO}_{2}$ film and $\mathrm{I}_{3}{ }^{-}$in the electrolyte. The chemical capacitance is $C_{\mu}=c_{\mu} L$ where $c_{\mu}$ is the inter-particle chemical capacitance. Therefore, the electron transport and recombination behavior may be quantitatively examined by fitting the Nyquist plot with ideal characteristics of the diffusion-recombination model with $R_{\mathrm{ct}} \gg R_{\mathrm{t}}$ and calculated according to the equation. ${ }^{26,28}$

From the fitted data, we could calculate the evolution of parameters such as electron diffusion coefficient $\left(D_{\mathrm{n}}\right)$, electron diffusion length $\left(L_{\mathrm{n}}\right)$ and charge collection efficiency $\left(\eta_{\mathrm{cc}}\right)$ according to the following equations: $:^{30,31}$

$$
\begin{gathered}
D_{\mathrm{n}}=L^{2} /\left(R_{\mathrm{t}} C_{\mu}\right) \\
L_{\mathrm{n}}=L \sqrt{R_{\mathrm{ct}} / R_{\mathrm{t}}} \\
\eta_{\mathrm{cc}}=1-R_{\mathrm{t}} /\left(R_{\mathrm{t}}+R_{\mathrm{ct}}\right)
\end{gathered}
$$

For an efficient cell, it is essential to have the longer $L_{\mathrm{n}}$, higher $\eta_{\mathrm{cc}}$ and $D_{\mathrm{n}}$ at any bias voltage between short circuit and open circuit. A simple illustrative electron transport and recombination scheme is shown in Fig. 5(a) based on the fitted $R_{\mathrm{t}}$ and $R_{\mathrm{ct}}$ with the calculated $D_{\mathrm{n}}, L_{\mathrm{n}}$, and $\eta_{\mathrm{cc}}$. As forward bias increases, more electrons are injected from the ITO substrate into the $\mathrm{TiO}_{2}$ conduction bands and the film is further charged by the accumulated electrons through the mesoscopic $\mathrm{TiO}_{2}$ nanoparticle networks. The degree of electron accumulation can be reflected by an upshift of quasi-Fermi level $\left(E_{\mathrm{Fn}}\right)$ of the $\mathrm{TiO}_{2}$ films. Therefore, the connectivity of $\mathrm{TiO}_{2}$ nanoparticles would also affect the shift of $E_{\mathrm{Fn}}$. According to trap-detrap model accounting for electron transport mechanism in DSCs, the potential difference between $E_{\mathrm{Fn}}$ and the conduction band influences electron transport. ${ }^{32}$ Hence, if the connectivity of $\mathrm{TiO}_{2}$ network is good enough, a relatively smaller forward bias is required to achieve similar $R_{\mathrm{t}}$ as well as $E_{\mathrm{Fn}}$. As shown in Fig. 5(b), less forward bias is required for DSCs prepared with compression until $100 \mathrm{MPa}$, which constitutes additional evidence of the improved connectivity of $\mathrm{TiO}_{2}$ nanoparticles. However, it is also observed that higher forward bias is required for cells with electrodes prepared using compression of 160 MPa than those prepared with $40 \mathrm{MPa}$ compression which indicates an increased electron transport resistance under excessive compression. The main reason for slowing electron transport behavior with compression of $160 \mathrm{MPa}$ is probably due to the reduced porosity $(22.3 \%)$ and pore size $(2.36 \mathrm{~nm})$, which retards diffusion of the electrolyte cation through the mesoscopic structure of $\mathrm{TiO}_{2}$ to neutralize the charged sites on the surface of $\mathrm{TiO}_{2}$ nanoparticles (Table S3 $\uparrow$ ); this which gives rise to higher $R_{\mathrm{t}}{ }^{33}$ On the other hand, no significant difference of $R_{\mathrm{ct}}$ is observed between the DSCs with compressed films, implying that almost similar recombination events occur for those cells, as shown in Fig. 5(c). Nevertheless, the smallest $R_{\mathrm{ct}}$ was obtained from cells made of uncompressed electrodes, which is in good agreement with the $V_{\mathrm{OC}}$ trends reported in Table 1. The competition between charge collection and charge recombination in the DSCs can be expressed in terms of $D_{\mathrm{n}}, L_{\mathrm{n}}$ and $\eta_{\mathrm{cc}}$ as displayed in Fig. 5(d)-(f). It can be concluded that cells made of compressed films present better diffusion and cells prepared with an electrode pressed at $100 \mathrm{MPa}$ exhibit the best performance. Additionally, a longer $L_{\mathrm{n}}$ was achieved from the compressed films than has been previously published for electrodes sintered at low temperature; ;,34-36 an $L_{\mathrm{n}}$ of approximately $25 \mu \mathrm{m}$ was achieved for the best performing cells of compressed films. This result confirms the benefit of the combined effect of chemical and physical sintering. The $\eta_{\mathrm{cc}}$ is evaluated by eqn (5); generally, higher $\eta_{\mathrm{cc}}$ is desirable for an efficient solar cell. ${ }^{31}$ As shown in Fig. 5(f), a great improvement of $\eta_{\mathrm{cc}}$ was demonstrated from compressed cells; $\eta_{\mathrm{cc}}$ of $95 \%$ was obtained for the cells compressed at $100 \mathrm{MPa}$. It is concluded that the synergetic approach combining physical sintering and chemical sintering effectively reinforced the connectivity of nanoparticles, resulting in an efficient electron transport through the $\mathrm{TiO}_{2}$ network. In order to further enhance the efficiency, the thickness of $\mathrm{TiO}_{2}$ film was tailored from $6.5 \mu \mathrm{m}$ up to $8.7 \mu \mathrm{m}$. By doing so, the $J_{\mathrm{sC}}$ increased from $9.67 \mathrm{~mA} \mathrm{~cm}^{-2}$
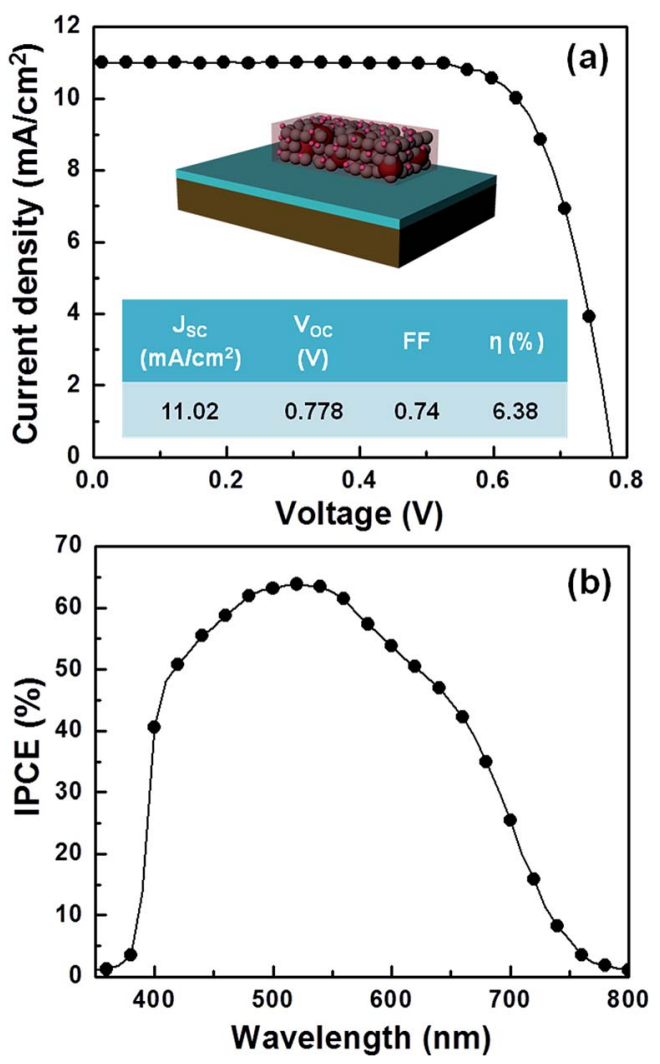

Fig. 6 The current-voltage curve (a) and IPCE (b) of the optimized cell with $\mathrm{TiO}_{2}$ film thickness of $8.72 \mu \mathrm{m}$. The schematic of the films' structure and composition is presented in inset along with the summarized photovoltaic properties. 
to $11.02 \mathrm{~mA} \mathrm{~cm}^{-2}$ and led to a $6.38 \%$ power conversion efficiency (Fig. 6(a) and (b)). The schematic of typical anode made of binder-free titania film is depicted in the Fig. 6(a) together with photovoltaic properties summarized in the inserted table. It is reasonable to expect further improvement of cell performance by replacing commercial P25 nanoparticles with better home-synthesized $\mathrm{TiO}_{2}$ nanoparticles.

\section{Conclusion}

We have shown that combining physical sintering with chemical sintering using nanoglue particles enhances nanocrystalline particle interconnectivity within $\mathrm{TiO}_{2}$ electrodes of dye solar cells. This approach has been applied for the preparation of photoanodes on a conductive ITO/PEN substrate for the generation of highly efficient plastic DSCs. The effect of compression on the structural and photovoltaic properties of the plastic DSCs was thoroughly investigated and rationalized. The electron transport resistance in compressed $\mathrm{TiO}_{2}$ films gradually decreased as the applied pressure increased from $0 \mathrm{MPa}$ to $100 \mathrm{MPa}$, revealing the enhanced interconnectivity of $\mathrm{TiO}_{2}$ nanoparticles. Furthermore, the improved electron diffusion coefficient, electron diffusion length, and charge-collection efficiency were also studied for $\mathrm{TiO}_{2}$ films prepared under different conditions. State-of-the-art cells on plastic substrates displaying power conversion efficiencies of $6.4 \%$ were realized employing widely-used and commercial-available P25 particles to prove the feasibility of the proposed method. Future work should focus on the optimization of the optical design of the cell to maximize light harvesting, as well as on the preparation of a fully flexible solar cell based on this synergic concept.

\section{Acknowledgements}

MJK acknowledge funding support from the Global Frontier R\&D Program on Center for Multiscale Energy System (2012M3A6A7054856) and 2015 University-Institute cooperation program funded by the National Research Foundation under the Ministry of Science, ICT \& Future Planning, Korea; this work was also supported by the KIST institutional programs and by Global Competitive Technology Development Program "Development of high drapability of textile type dye-sensitized solar cell materials and outdoor applications. (No. 10052064)" funded by the Ministry of Trade Industry \& Energy (MOTIE). YL acknowledges the financial support from the People Programme (Marie Curie Actions) of the European Union's Seventh Framework Programme FP7/2007-2013/ under REA grant agreement no. 622533. HM acknowledges funding from the European Research Council under the European Union's Seventh Framework Programme (FP7/2007-2013)/ERC grant agreement no. 307081 (POLIGHT) and the Spanish Ministry of Economy and Competitiveness under grant MAT2011-23593.

\section{References}

1 T. Miyasaka, M. Ikegami and Y. Kijitori, J. Electrochem. Soc., 2007, 154, A455-A461.
2 T. Yamaguchi, N. Tobe, D. Matsumoto and H. Arakawa, Chem. Commun., 2007, 4767-4769.

3 X. Li, H. Lin, J. Li, N. Wang, C. Lin and L. Zhang, J. Photochem. Photobiol., A, 2008, 195, 247-253.

4 N. G. Park, K. M. Kim, M. G. Kang, K. S. Ryu, S. H. Chang and Y. J. Shin, Adv. Mater., 2005, 17, 2349.

5 Y. Li, W. Lee, D. K. Lee, K. Kim, N. G. Park and M. J. Ko, Appl. Phys. Lett., 2011, 98, 103301.

6 Y. Li, K. Yoo, D.-K. Lee, J. Y. Kim, H. Kim, B. Kim and M. J. Ko, Nanoscale, 2013, 5, 4711-4719.

7 H. C. Weerasinghe, P. M. Sirimanne, G. V. Franks, G. P. Simon and Y. B. Cheng, J. Photochem. Photobiol., A, 2010, 213, 30-36.

8 H. Lindstrom, E. Magnusson, A. Holmberg, S. Sodergren, S. E. Lindquist and A. Hagfeldt, Sol. Energy Mater. Sol. Cells, 2002, 73, 91-101.

9 J. Halme, J. Saarinen and P. Lund, Sol. Energy Mater. Sol. Cells, 2006, 90, 887-899.

10 X. Zhao, H. Lin, X. Li and J. Li, Electrochim. Acta, 2011, 56, 6401-6405.

11 Z. Dongshe, T. Yoshida, T. Oekermann, K. Furuta and H. Minoura, Adv. Funct. Mater., 2006, 16, 1228-1234.

12 H.-Y. Jin, J.-Y. Kim, J. A. Lee, K. Lee, K. Yoo, D.-K. Lee, B. Kim, J. Y. Kim, H. Kim, H. J. Son, J. Kim, J. A. Lim and M. J. Ko, Appl. Phys. Lett., 2014, 104, 43902.

13 H. C. Weerasinghe, F. Huang and Y.-B. Cheng, Nano Energy, 2013, 2, 174-189.

14 H.-P. Jen, M.-H. Lin, L.-L. Li, H.-P. Wu, W.-K. Huang, P.-J. Cheng and E. W.-G. Diau, ACS Appl. Mater. Interfaces, 2013, 5, 10098-10104.

15 M. J. Yun, S. I. Cha, S. H. Seo and D. Y. Lee, Sci. Rep., 2014, 4, 5322.

16 T. Yamaguchi, N. Tobe, D. Matsumoto, T. Nagai and H. Arakawa, Sol. Energy Mater. Sol. Cells, 2010, 94, 812-816.

17 H. Arakawa, T. Yamaguchi, T. Sutou, Y. Koishi, N. Tobe, D. Matsumoto and T. Nagai, Curr. Appl. Phys., 2010, 10, S157-S160.

18 H.-W. Chen, C.-Y. Hsu, J.-G. Chen, K.-M. Lee, C.-C. Wang, K.-C. Huang and K.-C. Ho, J. Power Sources, 2010, 195, 6225-6231.

19 K. D. Benkstein, N. Kopidakis, J. van de Lagemaat and A. J. Frank, J. Phys. Chem. B, 2003, 107, 7759-7767.

20 J. van de Lagemaat, K. D. Benkstein and A. J. Frank, J. Phys. Chem. B, 2001, 105, 12433-12436.

21 D. Bouvard and F. F. Lange, Phys. Rev. A: At., Mol., Opt. Phys., 1992, 45, 5690-5693.

22 K. Fan, C. Gong, T. Peng, J. Chen and J. Xia, Nanoscale, 2011, 3, 3900-3906.

23 X. Li, H. Lin, J. Li, X. Li, B. Cui and L. Zhang, J. Phys. Chem. C, 2008, 112, 13744-13753.

24 A. G. Agrios and A. Hagfeldt, J. Phys. Chem. C, 2008, 112, 10021-10026.

25 J. Bisquert, J. Phys. Chem. B, 2002, 106, 325-333.

26 F. Fabregat-Santiago, J. Bisquert, G. Garcia-Belmonte, G. Boschloo and A. Hagfeldt, Sol. Energy Mater. Sol. Cells, 2005, 87, 117-131. 
27 T. Hoshikawa, M. Yamada, R. Kikuchi and K. Eguchi, J. Electrochem. Soc., 2005, 152, E68-E73.

28 M. Adachi, M. Sakamoto, J. Jiu, Y. Ogata and S. Isoda, J. Phys. Chem. B, 2006, 110, 13872-13880.

29 J. Bisquert, G. Garcia-Belmonte, F. Fabregat-Santiago, N. S. Ferriols, P. Bogdanoff and E. C. Pereira, J. Phys. Chem. B, 2000, 104, 2287-2298.

30 Q. Wang, S. Ito, M. Graetzel, F. Fabregat-Santiago, I. MoraSero, J. Bisquert, T. Bessho and H. Imai, J. Phys. Chem. B, 2006, 110, 25210-25221.

31 Q. Wang, Z. Zhang, S. M. Zakeeruddin and M. Graetzel, J. Phys. Chem. C, 2008, 112, 7084-7092.
32 J. Bisquert, F. Fabregat-Santiago, I. Mora-Sero, G. GarciaBelmonte and S. Gimenez, J. Phys. Chem. C, 2009, 113, 17278-17290.

33 F. Fabregat-Santiago, J. Bisquert, L. Cevey, P. Chen, M. Wang, S. M. Zakeeruddin and M. Graetzel, J. Am. Chem. Soc., 2009, 131, 558-562.

34 S. Nakade, M. Matsuda, S. Kambe, Y. Saito, T. Kitamura, T. Sakata, Y. Wada, H. Mori and S. Yanagida, J. Phys. Chem. B, 2002, 106, 10004-10010.

35 H.-W. Chen, Y.-T. Liao, J.-G. Chen, K. C. W. Wu and K.-C. Ho, J. Mater. Chem., 2011, 21, 17511-17518.

36 A. R. Pascoe, F. Huang, N. W. Duffy and Y.-B. Cheng, J. Phys. Chem. C, 2014, 118, 15154-15161. 